\title{
Premature Failure of Apedwa-Bunsu Junction Section of N6 in Ghana: Some Notes for Consideration
}

\author{
Yaw Adubofour Tuffour ${ }^{1}$, Nana Kwesi Agyepong ${ }^{2}$, Daniel Atuah Obeng ${ }^{1}$ \\ ${ }^{1}$ Department of Civil Engineering, Kwame Nkrumah University of Science and Technology, Kumasi, Ghana \\ ${ }^{2}$ Materials Division, Ghana Highway Authority, Ministry of Roads and Highways, Accra, Ghana
}

\section{Email address:}

yat@engineer.com (Y. A. Tuffour), k_agyeponguk@yahoo.co.uk (N. K. Agyepong), obengatuah@yahoo.co.uk (D. A. Obeng)

${ }^{*}$ Corresponding author

\section{To cite this article:}

Yaw Adubofour Tuffour, Nana Kwesi Agyepong, Daniel Atuah Obeng. Premature Failure of Apedwa-Bunsu Junction Section of N6 in Ghana: Some Notes for Consideration. American Journal of Civil Engineering. Vol. 4, No. 3, 2016, pp. 84-91. doi: 10.11648/j.ajce.20160403.14

Received: April 13, 2016; Accepted: April 25, 2016; Published: May 11, 2016

\begin{abstract}
This study investigated premature and continual failure of the Apedwa-Bunsu Junction section of Route N6 in Ghana despite an earlier maintenance intervention which included geotextile installation and placement of a new wearing course. It involved a condition survey, density, asphalt content, gradation, stiffness modulus and Falling Weight Deflectometer (FWD) tests on the section. The condition survey revealed cracking (alligator, transverse and longitudinal), ravelling, potholes, rutting and shoving as the predominant defects on the road. The density tests on the bituminous layers revealed relative compaction levels which, in most cases, did not meet the minimum required by the technical specifications despite the additional densification by traffic. The poor compaction was corroborated by high pavement deflections from the FWD device. Asphalt cores revealed a friable dense bituminous macadam (DBM) layer although bitumen extraction tests indicated all design asphalt contents were met. Lack of inter-particle cohesion within the DBM layer was suggestive of stripping damage to the asphalt concrete. Some samples of the crushed rock base contained plastic fines and fines content that exceeded specification limits. High stiffness modulus values of the bituminous layers suggested possible premature aging of the asphalt binder which probably accelerated crack development. An earlier intervention in the form of placement of geotextile in the wearing course failed to arrest cracking because the material had been placed at a shallow depth rendering it ineffective. It was concluded that inadequate compaction of the bituminous layers and the use of crushed rock and other pavement materials that did not wholly meet the technical specifications were the root causes of the premature failure of the section.
\end{abstract}

Keywords: Premature Failure, Compaction, Cracking, Relative Density, Rutting, Shoving

\section{Introduction}

Route N6 in Ghana is a major transport link between the north and south of the country and also an important trade route linking Ghana to several of her West African neighbours to the north. Safety and uninterrupted flow on N6 are very important as the route forms part of the trans-West Africa trade route. In 2002, the Ghana Highway Authority (GHA) awarded the contract for the construction of the Apedwa-Bunsu Junction Road, which is $23 \mathrm{~km}$ long, as a new alignment to the Apedwa-Potroase-Bunsu Junction section of N6 which was accident-prone, to improve safety on N6 as a whole. The pavement structure consists of $40 \mathrm{~mm}$ wearing course, $60 \mathrm{~mm}$ binder course, $80 \mathrm{~mm}$ dense bituminous macadam (DBM), 200mm crushed stone base and 200mm natural gravel sub-base. Construction was completed and the road opened to traffic in 2004 but since then, performance has been poor.

Within the first few years of its service life, the section began to experience mainly cracking, ravelling and rutting although there were other minor defects. In 2007, the Ghana Highway Authority (GHA) initiated investigation into the causes of the premature failures the outcome of which led to the removal of the wearing course, installation of geotextile as reinforcement to arrest the cracks and placement of a new layer of wearing course. The intervention notwithstanding, the distresses continued and accelerated. By 2011, deterioration had become so severe at several locations as to prompt another investigation into the causes of the failures. 
Premature failures of asphalt overlays within the first few years of in-service life are not uncommon and have been well investigated by several researchers. Himeno and Watnabe [1] have noted that fatigue failure can initiate at the top of a new asphalt concrete layer with low stiffness arising from poor compaction. According to Button and Lytton [2], distresses in the wheel path and rapid deterioration of asphalt overlays may arise if moisture accumulates through evapo-transpiration from beneath or infiltration from the top in hot-mix asphalt susceptible to moisture damage. The accumulated water tends to cause stripping damage and weakens the pavement structure. In cold regions, freeze-thaw cycles may induce thermal cracking and moisture distresses to reduce the capacity of asphalt pavements [3]. Excess asphalt content in bituminous layers, particularly the wearing course, and a change in aggregate gradation may lead to early rutting [4].

Early brittleness, cracking and stripping in an asphalt pavement due to the use of super fine filler have been reported by Horak and Emery [5]. According to Muench and Willoughby [6], construction-related temperature differentials may lead to the placement of cooler mats that may resist adequate compaction and result in localised open-textured surfaces having high air voids. Generally, overlays with high air voids content have a higher risk of moisture damage than those with low air voids content due to the ease of water penetration [7]. Oxidative aging may also accelerate in such overlays leading to binder embrittlement and subsequent cracking and ravelling. Significant rutting due to densification under traffic, especially for thick lifts, may occur in new overlays compacted to voids content higher than the long-term air voids content pertaining to the mix design [8]. Pavements with excessive fines and excessive asphalt content as well as improper aggregate grading are also likely to suffer early shear deformation if they come under heavy loads and high tyre pressures [8]. In some cases, inadequate bonding between the base and intermediate asphalt concrete lifts, arising from inadequate or non-uniform tack coat application, could lead to middle-up cracking and cause unanticipated pavement failure to occur [9]. De-bonding and slippage failure could also occur if tack coat application was non-uniform or the material was removed by construction trucks before placement of the asphalt concrete lift [10].

This paper reports on the outcome of the second investigation into the failures on the Apedwa-Bunsu Junction section of N6. It is expected that the outcome of the study would provide some useful notes for better construction practices that would reduce the incidence of premature distresses in future asphalt pavement constructions in the country.

\section{Materials and Methods}

\subsection{Road Condition Survey}

A thorough condition survey was carried out on both the north- and south-bound lanes of the Apedwa-Bunsu Junction section of N6 to note the types of distresses and extent of coverage. The survey also provided opportunity to map out uniform sub-sections and determine locations for sampling.

\subsection{Uniform Sectioning and Sampling}

The condition survey was used as a basis for dividing the section under study into uniform sub-sections with seemingly pristine conditions to enable samples to be taken for laboratory analysis. In all, a total of 10 uniform sub-sections with 10 sampling locations as detailed in Table 1 were selected.

Table 1. Details of uniform sections and sampling points.

\begin{tabular}{lll}
\hline Km & Length $(\mathbf{m})$ & Sampling Point \\
\hline $6+000-7+000$ & 1000 & $6+750$ \\
$9+300-10+900$ & 1600 & $10+050$ \\
$10+900-11+400$ & 500 & $10+500$ \\
$12+800-13+600$ & 800 & $13+250$ \\
$14+200-15+700$ & 1500 & $14+130$ \\
$15+700-16+200$ & 500 & $16+000$ \\
$17+000-17+800$ & 800 & $17+750$ \\
$17+800-18+000$ & 200 & $18+000$ \\
$18+000-19+000$ & 1000 & $18+750$ \\
$19+000-21+000$ & 2000 & $20+750$ \\
\hline
\end{tabular}

\subsection{Trial Pitting}

Layer materials for testing were obtained through trial pitting. Bituminous materials as well as unbound pavement layer materials beneath the asphalt concrete layers were sampled. Of the 10 locations selected for sampling, 5 were sited on the south-bound lane and the other 5 on the north-bound lane. Samples were taken at depths corresponding to the wearing and binder courses, the dense bituminous macadam (DBM) layer, the crushed stone base (CSB) layer, the sub-base layer and the sub-grade.

\subsection{Coring of Asphalt Concrete Layers}

Asphalt cores were taken at locations adjacent to the trial pits for laboratory testing. In all, 4 cores were taken at each of the 10 locations. Cores for the wearing course, the binder and the DBM layers were separated. Two cores out of the four samples taken at each location were used for density tests and the remaining for indirect tensile stiffness modulus tests.

\subsection{Falling Weight Deflectometer Test}

At locations where the elastic modulus and surface deflections were measured, the FWD equipment was set up and then a load pulse applied to the pavement through a piston by means of a computerised system attached to the device. Deflections were picked up by seven geophones. The elastic modulus and surface deflection measurements were taken on both the north-bound and south-bound lanes.

\subsection{Indirect Tensile Stiffness Modulus Test}

Asphalt concrete cores taken from the field were prepared and tested in accordance with BS DD213 [11]. Deformations 
during testing were measured by high-speed transducers.

\subsection{Other Laboratory Tests}

Other laboratory tests conducted on the field samples were:

- Bitumen extraction

- Grading of the residual aggregates after bitumen extraction

- Grading and Atterberg limits of non-bituminous layer materials

\section{Results and Discussion}

\subsection{Distress Types}

The major distress identified on the study section and their prevalence in terms of percentage of road length coverage have been summarised in Table 2. Figures 1-5 show graphically how severe some of the distresses were.

Table 2. Distress types and coverage on study section.

\begin{tabular}{lllll}
\hline \multirow{2}{*}{ Distress Type } & \multicolumn{2}{l}{ North-bound Lane } & \multicolumn{2}{l}{ South-bound Lane } \\
\cline { 2 - 5 } & $\begin{array}{l}\text { Length } \\
(\mathbf{m})\end{array}$ & $\begin{array}{l}\text { Coverage } \\
\mathbf{( \% )}\end{array}$ & $\begin{array}{l}\text { Length } \\
(\mathbf{m})\end{array}$ & $\begin{array}{l}\text { Coverage } \\
(\mathbf{\%})\end{array}$ \\
\hline $\begin{array}{l}\text { Raveling } \\
\text { Longitudinal \& }\end{array}$ & 2280 & 9.9 & 1320 & 5.7 \\
$\begin{array}{l}\text { Transverse Cracks } \\
\text { Alligator Cracks }\end{array}$ & 15070 & 65.5 & 15570 & 67.7 \\
Potholes & 6720 & 29.2 & 4340 & 18.9 \\
Rutting & $\begin{array}{l}\text { Localised } \\
\text { Shoving }\end{array}$ & - & & - \\
\hline & 10500 & 45.7 & 10280 & 50.3 \\
\hline
\end{tabular}

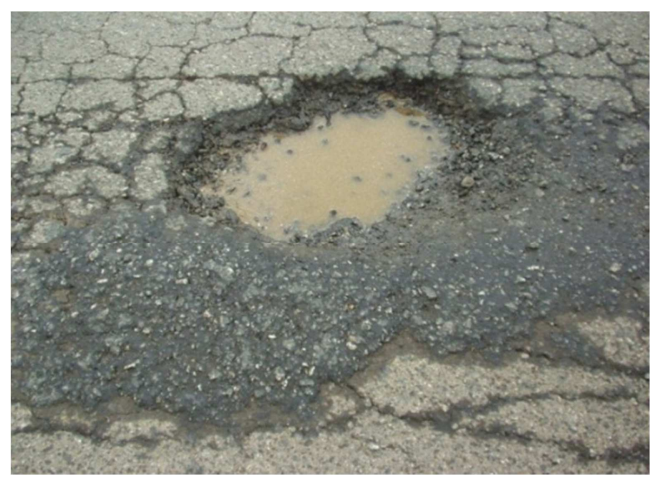

Figure 1. Alligator cracks with pothole development.

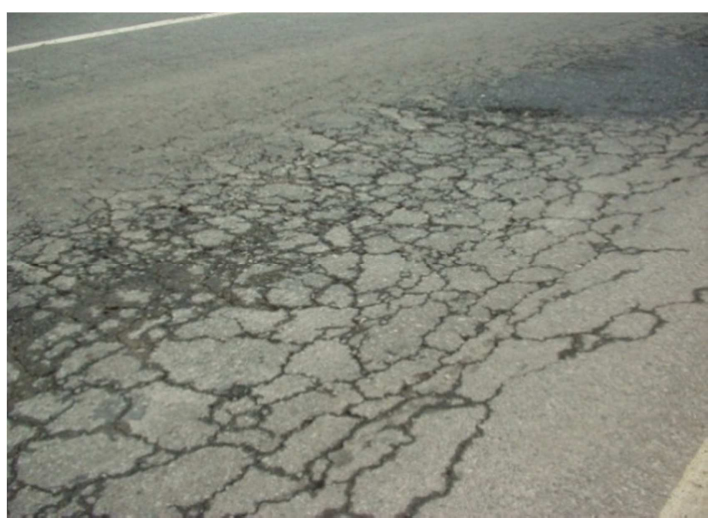

Figure 2. Extensive alligator cracks in wearing course.

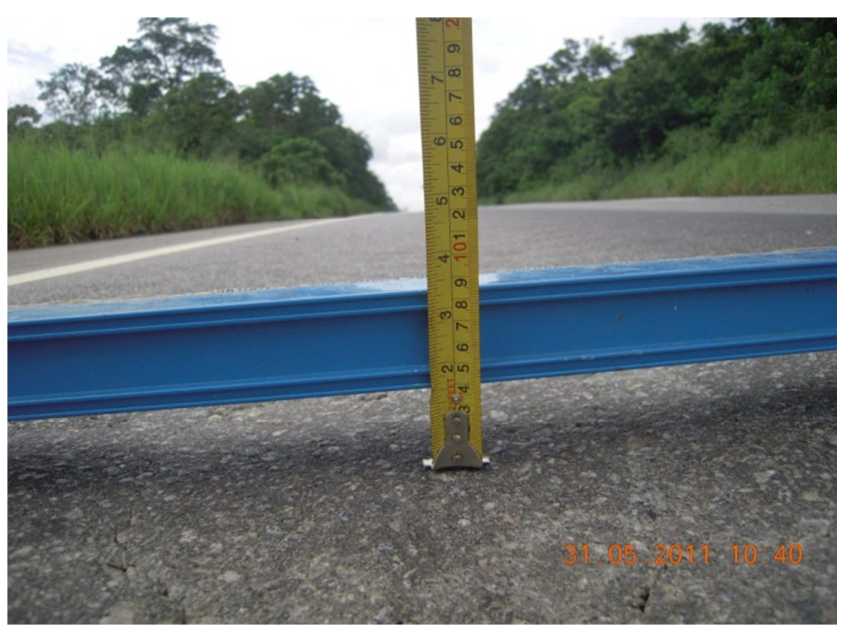

Figure 3. Rut in wearing course.

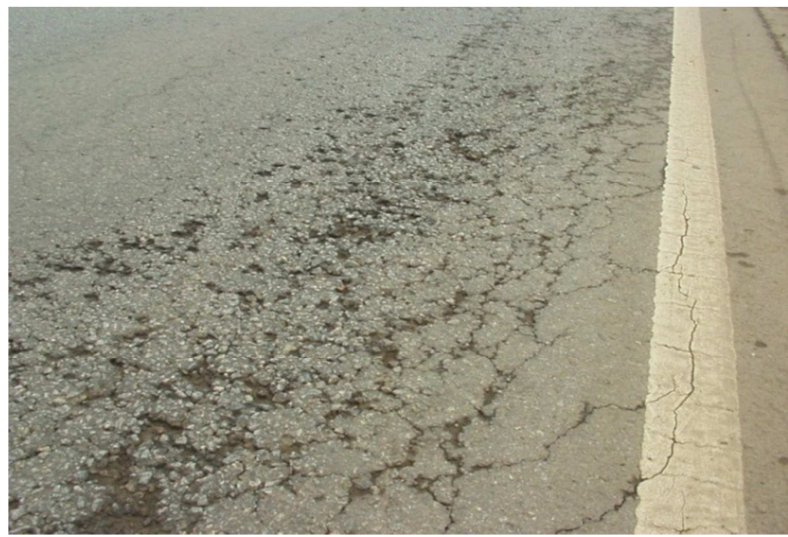

Figure 4. Ravelling with incipient pothole development.

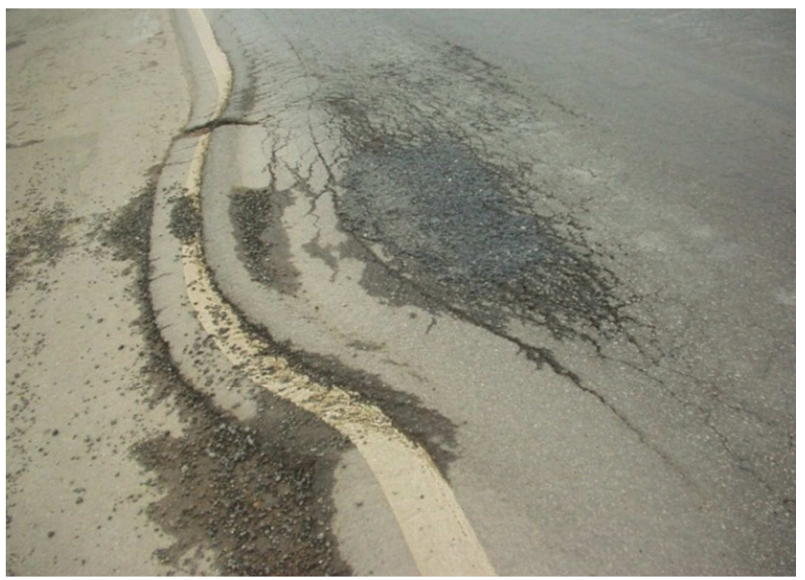

Figure 5. Structural failure and shoving of outer edge of surface course.

Overall, the following were established from the survey:

- Transverse and longitudinal cracking was very extensive in both travelled lanes and affected a greater length of the section.

- In terms of structural deformation, rutting dominated on both travelled lanes while shear failure and associated shoving tended to be confined to the outer edges of the wearing course.

- Alligator cracking was prevalent on both travelled lanes but affected a longer length of the north-bound lane than 
the south-bound lane.

- Rutting was prevalent on both travelled lanes but affected a slightly longer length of the north-bound lane than the south-bound lane.

At some locations, the presence of ruts and cracks allowed run-off to seep into the pavement structure to saturate the underlying layers which became evident during the trial pitting (see Figure 6). Differences in prevalence of the distresses on the two travelled lanes could not be linked to differences in lane loading as this portion of N6 comes under heavy goods transport in both travelled directions almost equally. Besides, portions of N6 abutting the study section and constructed earlier under a different contract did not exhibit many of the observed defects on the study section, despite coming under the same loading regime.

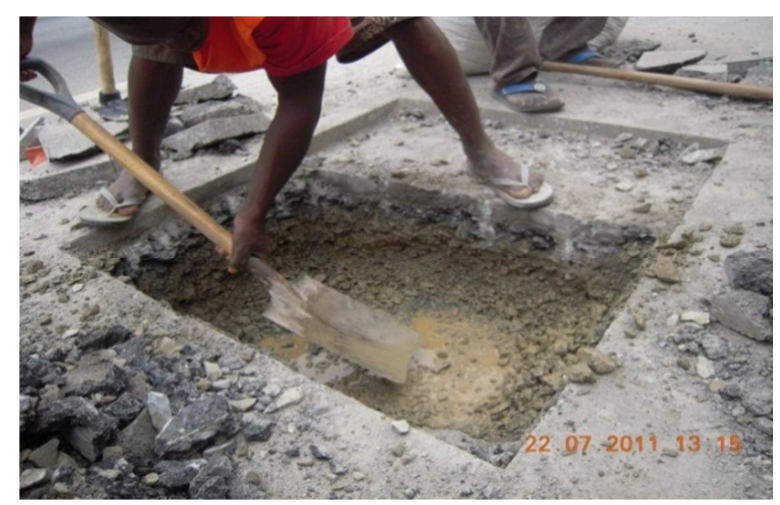

Figure 6. Trial pit showing water-soaked crushed stone base.

\subsection{Level of Compaction of Bituminous Layers}

The bulk densities of the cores taken from the uniform sub-sections have been detailed in Table 3 for the wearing, binder and DBM layers.

Table 3. Bulk densities of bituminous layers.

\begin{tabular}{llll}
\hline \multirow{2}{*}{ Km } & \multicolumn{3}{l}{ Bulk Density $\left(\mathbf{k g} / \mathbf{m}^{\mathbf{3}}\right)$} \\
\cline { 2 - 4 } & Wearing Course & Binder Course & DBM Layer \\
\hline $6+750$ & 2450 & 2378 & 2341 \\
$10+050$ & 2310 & 2382 & 2347 \\
$10+500$ & 2280 & 2288 & 2310 \\
$13+250$ & 2355 & 2310 & 2388 \\
$14+130$ & 2276 & 2176 & 2378 \\
$16+000$ & 2368 & 2257 & 2411 \\
$17+750$ & 2373 & 2302 & 2418 \\
$18+000$ & 2431 & 2326 & 2248 \\
$18+750$ & 2401 & 2346 & 2403 \\
$20+750$ & 2352 & 2350 & 2366 \\
\hline
\end{tabular}

\section{a) Wearing Course}

The bulk density values ranged between $2276 \mathrm{~kg} / \mathrm{m}^{3}$ and $2450 \mathrm{~kg} / \mathrm{m}^{3}$ with an average value of $2360 \mathrm{~kg} / \mathrm{m}^{3}$. The reference laboratory bulk density for the hot-mix asphalt used for the paving operation was $2490 \mathrm{~kg} / \mathrm{m}^{3}$. This translates to relative compaction achieved in the field that ranged between $91 \%$ and $98 \%$. Cored samples from 5 out of the 10 sample locations had relative compaction values below the minimum of $95 \%$ specified by the special technical specifications. b) Binder Course

The density values ranged between $2176 \mathrm{~kg} / \mathrm{m}^{3}$ and $2382 \mathrm{~kg} / \mathrm{m}^{3}$ with an average value of $2312 \mathrm{~kg} / \mathrm{m}^{3}$. The laboratory bulk density achieved for the paving mix was $2497 \mathrm{~kg} / \mathrm{m}^{3}$. Based on the densities of the cores taken from the road, the relative compaction achieved ranged between $87 \%$ and $96 \%$, with 8 out of 10 sample locations (80\%) having relative compaction values that were below the minimum of $95 \%$ specified by the special technical specifications.

c) DBM Layer

The density of the DBM layer ranged between $2248 \mathrm{~kg} / \mathrm{m}^{3}$ and $2418 \mathrm{~kg} / \mathrm{m}^{3}$ with an average value of $2361 \mathrm{~kg} / \mathrm{m}^{3}$. The bulk density of the samples taken from the hot-mix plant for the paving operation was $2497 \mathrm{~kg} / \mathrm{m}^{3}$. The relative compaction achieved for the layer ranged between $90 \%$ and $97 \%$. Relative compaction values for 4 locations out of the 10 sampled were below the minimum specified by the special technical specifications.

It was noted that the cored DBM layer tended to be friable with the mix hardly able to hold together. This suggested a lack of cohesion caused by stripping. There was also evidence of pitting on the cored surface suggesting material segregation and poor compaction during placement as well as stripping (see Fig. 7).

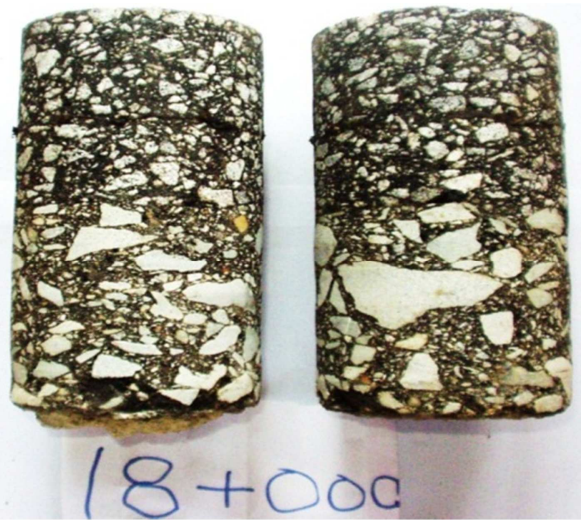

Figure 7. Asphalt cores with pitted surfaces.

The low relative compaction values associated with the bituminous layers are indicative of inadequate compaction during construction. It is believed that the poor compaction rendered the DBM layer permeable and probably made it easy for water to penetrate the pavement structure to cause stripping damage. Even though Chen [12] has cautioned that density alone may not engender quality construction, nevertheless, dense gradation and high density are important for achieving minimum permeability [2]. It is believed that moisture damage may have led to loss of inter-particle cohesion within the DBM layer causing it to behave essentially like a compacted granular layer.

\subsection{Bitumen Content of Bituminous Layers}

Table 4 contains the results of the bitumen content for the bituminous samples taken from the homogenous sections without distinction between the two travelled lanes. 
Table 4. Bitumen content of bituminous layers.

\begin{tabular}{llll}
\hline \multirow{2}{*}{ Km } & \multicolumn{3}{l}{ Bitumen Content (\%) } \\
\cline { 2 - 4 } & Wearing Course & Binder Course & DBM \\
\hline $6+750$ & 5.1 & 4.8 & 3.9 \\
$10+050$ & 5.1 & 5.2 & 4.2 \\
$10+500$ & 5.1 & 4.7 & 4.3 \\
$13+250$ & 5.0 & 4.5 & 4.1 \\
$14+130$ & 5.0 & 4.9 & 4.2 \\
$16+000$ & 5.2 & 4.9 & 4.0 \\
$17+750$ & 5.2 & 4.8 & 4.2 \\
$18+000$ & 5.1 & 4.8 & 3.9 \\
$18+750$ & 5.1 & 4.9 & 4.1 \\
$20+750$ & 5.1 & 4.9 & 4.2 \\
\hline
\end{tabular}

a) Wearing and Binder Courses

The asphalt content of the wearing course ranged between $5.0 \%$ and $5.2 \%$ with a mean of $5.1 \%$ which was the same as the mix design value. In the case of the binder course, it ranged between $4.5 \%$ and $4.9 \%$ with a mean value of $4.8 \%$. The mean was the same as the mix design value.

b) Dense bituminous macadam

The asphalt content values ranged between $3.9 \%$ and $4.3 \%$ with a mean of $4.1 \%$. This differed only marginally from the mix design value of $4.0 \%$ but was within tolerance limits.

\subsection{Elastic Moduli of Bituminous Layers}

\subsubsection{Indirect Tensile Stiffness Modulus}

Table 5 contains the Indirect Tensile Stiffness Modulus as measured in the Indirect Tensile Stiffness test. In comparison, results from similar tests conducted at the GHA Materials Lab on new un-aged asphalt concrete briquettes yielded values in the range of 4,000MPa-8,000MPa.
Table 5. Indirect Tensile Stiffness Modulus.

\begin{tabular}{llll}
\hline \multirow{2}{*}{ Km } & \multicolumn{3}{l}{ Stiffness Modulus (MPa) } \\
\cline { 2 - 4 } & Wearing Course & Binder Course & BDM \\
\hline $6+750$ & 30362 & 21056 & 16269 \\
$10+050$ & 25803 & 12504 & 10557 \\
$10+500$ & 15052 & 20472 & 6846 \\
$13+250$ & 11959 & 16255 & 18820 \\
$14+130$ & 23747 & 20999 & 16505 \\
$16+000$ & 13530 & 19549 & 17714 \\
$17+750$ & 21980 & 27351 & 20251 \\
$18+000$ & 15294 & 27531 & 13483 \\
$18+750$ & 21894 & 14598 & 15255 \\
$20+750$ & 11345 & 18028 & 17488 \\
\hline
\end{tabular}

In general, high stiffness indicates brittle material and, hence, high cracking potential. This suggests that the bituminous layers had undergone premature aging which must have contributed to crack development.

\subsubsection{Moduli from FWD Device}

Table 6 details the elastic moduli obtained from the FWD device. The average value for the binder and wearing course considered as a composite layer is about $4,200 \mathrm{MPa}$ whilst that for the DBM layer is about $430 \mathrm{MPa}$, a tenfold difference. The average value $350 \mathrm{MPa}$ for the crushed stone base was similar to that of the DBM layer. The low modulus of the DBM layer corroborates the assertion made earlier that the poor compaction and the lack of cohesion caused by stripping within the DBM layer made the layer behave much like a granular layer and not a bound layer.

Table 6. Elastic Moduli of Pavement Layers from FWD Tests.

\begin{tabular}{|c|c|c|c|c|c|c|c|c|c|c|}
\hline \multirow{3}{*}{ Km } & \multicolumn{10}{|c|}{ Elastic Modulus (MPa) } \\
\hline & \multicolumn{2}{|c|}{ Wearing \& Binder Course } & \multirow{2}{*}{$\begin{array}{l}\text { DBM } \\
\text { NBL } \\
\end{array}$} & \multicolumn{3}{|c|}{ CSB } & \multicolumn{2}{|c|}{ Sub-base } & \multicolumn{2}{|c|}{ Sub-grade } \\
\hline & NBL & SBL & & SBL & NBL & SBL & NBL & SBL & NBL & SBL \\
\hline $6+750$ & 5586 & 2867 & 591 & 384 & 489 & 307 & 270 & 162 & 134 & 81 \\
\hline $10+050$ & 7554 & 8997 & 400 & 623 & 331 & 498 & 183 & 264 & 141 & 142 \\
\hline $10+500$ & 1977 & 2967 & 486 & 509 & 402 & 407 & 222 & 216 & 230 & 232 \\
\hline $13+250$ & 3666 & 2488 & 447 & 328 & 369 & 262 & 204 & 139 & 151 & 132 \\
\hline $14+130$ & 3348 & 4753 & 400 & 448 & 330 & 359 & 182 & 190 & 179 & 99 \\
\hline $17+750$ & 2786 & 7198 & 299 & 511 & 248 & 409 & 137 & 217 & 80 & 80 \\
\hline $18+000$ & 2072 & 4679 & 429 & 545 & 355 & 437 & 196 & 231 & 62 & 78 \\
\hline $18+750$ & 4943 & 4716 & 349 & 425 & 288 & 341 & 159 & 180 & 40 & 45 \\
\hline $20+750$ & 3796 & - & 419 & 393 & 347 & 314 & 192 & 166 & 74 & 79 \\
\hline
\end{tabular}

$\mathrm{NBL}=$ north-bound lane, $\mathrm{SBL}=$ south-bound lane

Table 7. Surface deflections from FWD tests.

\begin{tabular}{lll}
\hline \multirow{2}{*}{$\mathbf{K m}$} & \multicolumn{2}{l}{ Maximum Deflection (microns) } \\
\cline { 2 - 3 } & North-bound Lane & South-bound Lane \\
\hline $6+750$ & 318 & 444 \\
$10+050$ & 385 & 255 \\
$10+500$ & 309 & 366 \\
$13+250$ & 364 & 469 \\
$14+130$ & 411 & 410 \\
$16+000$ & 485 & 474 \\
$17+750$ & 519 & 338 \\
$18+000$ & 421 & 347 \\
$18+750$ & 476 & 477 \\
$20+750$ & 425 & 435 \\
\hline
\end{tabular}

\subsection{Surface Deflections}

The deflections on the sections obtained from the FWD device have been shown in Table 7. The values refer to the maximum deflections measured of the deflection bowl and ranged between 300 to 520 microns for the north-bound lane and 200 to 480 microns for the south-bound lane.

Typical deflection values obtained by the Ghana Highway Authority (GHA) on some roads with similar age and pavement structure were in the range of 198-210 microns. The high values recorded in the current study reflect a weak 
composite pavement structure.

\subsection{Properties of Unbound Granular Materials}

\subsubsection{Atterberg Limits}

Table 8 contains data on the Atterberg limits (LL and PI) of the unbound pavement materials. It is seen from the table that the CSB material had a PI of the order of $7 \%-8 \%$ even though the specification required non plastic material. The values suggest the presence of some amount of clayey material. In the case of the sub-base material, the PI value was essentially the same as the maximum specified and therefore, the material may be considered as being of marginal quality with respect to Atterberg limits. The subgrade material, on the other hand, met the specification requirement.

Table 8. Atterberg limits of unbound pavement materials.

\begin{tabular}{lllllll}
\hline & CSB & \multicolumn{3}{c}{ Sub-base } & \multicolumn{2}{l}{ Sub-grade } \\
\hline $\mathbf{K m}$ & PI & LL & PI & LL & PI & LL \\
\hline $6+750$ & & - & - & - & - & - \\
$10+050$ & 7.5 & - & 11.9 & 33.6 & 21.3 & 44.7 \\
$10+500$ & 7.5 & - & 10.3 & 28 & - & - \\
$13+250$ & 7.6 & - & 13.7 & 35.2 & - & - \\
$14+130$ & 7.4 & - & 12.4 & 30.5 & 21.2 & 45.8 \\
$16+000$ & 7.3 & - & 11 & 28.2 & - & - \\
$17+750$ & 7.6 & - & - & - & 23.9 & 51 \\
$18+000$ & 7.7 & - & 12.9 & 30 & - & - \\
$18+750$ & 7.3 & - & - & - & - & - \\
$20+750$ & 7 & - & 10 & 28.7 & - & - \\
\hline
\end{tabular}

\subsubsection{Particle Size Distribution}

a) Wearing and Binder Courses

Figures 8 and 9 show the particle size distribution curves for samples of the wearing course and binder course materials, respectively, after bitumen extraction. The curves have been superimposed on the corresponding gradation envelope per the Ministry of Roads and Highways Specification (MRH) [13]. It is seen that all the curves essentially fell within the gradation envelope, although in the case of the binder course material, there was slight violation for some of the samples in the fine fraction content. In addition, most of the sample curves tended to gravitate a bit more toward the upper limits of the specification size ranges.

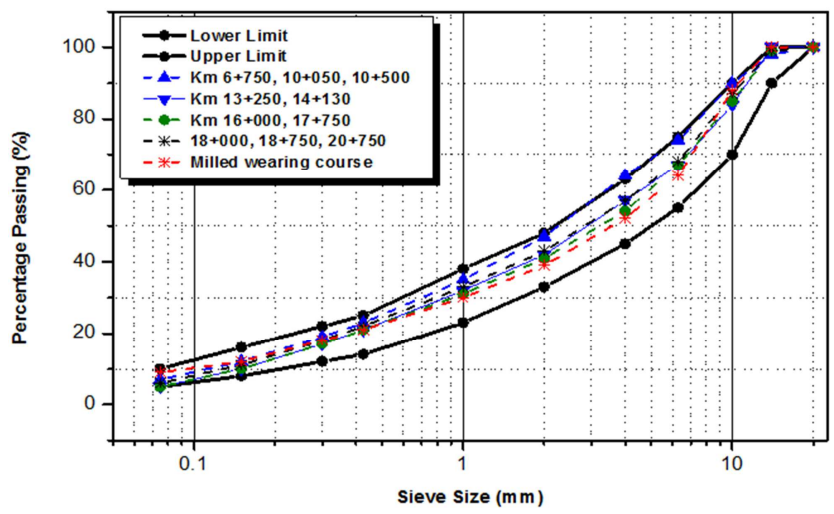

Figure 8. Particle size distribution of wearing course aggregate.

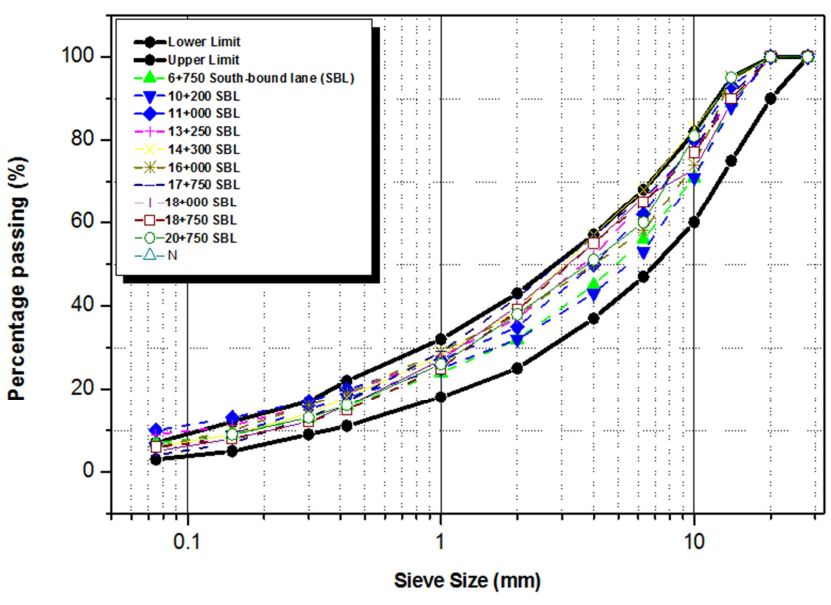

Figure 9. Particle size distribution of binder course aggregate.

b) DBM Layer

Figure 10 shows the particle size distribution of the residual aggregates of the DBM layer after bitumen extraction. While most of the samples had the particle size falling within the specification envelope, a few fell outside. Also, most of the samples with size distribution falling within the envelope tended to gravitate toward the upper limit of the size ranges.

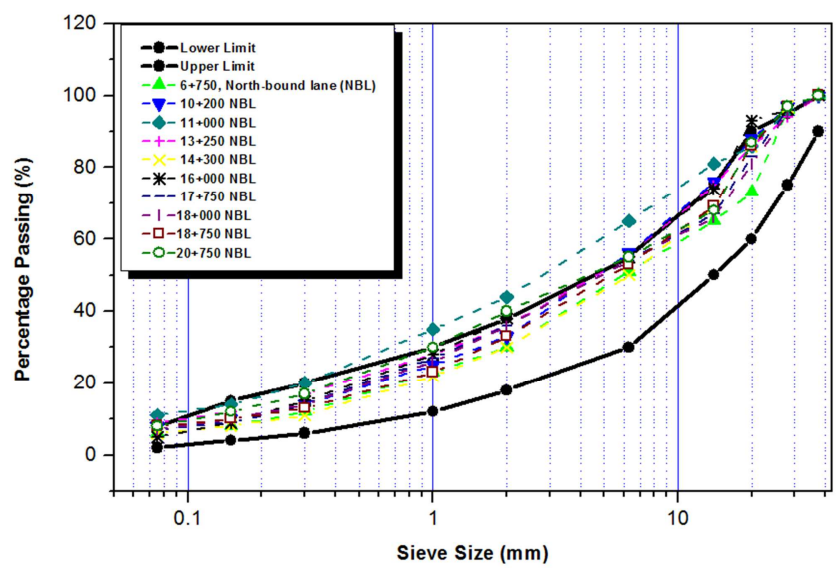

Figure 10. Particle size distribution of DBM aggregate.

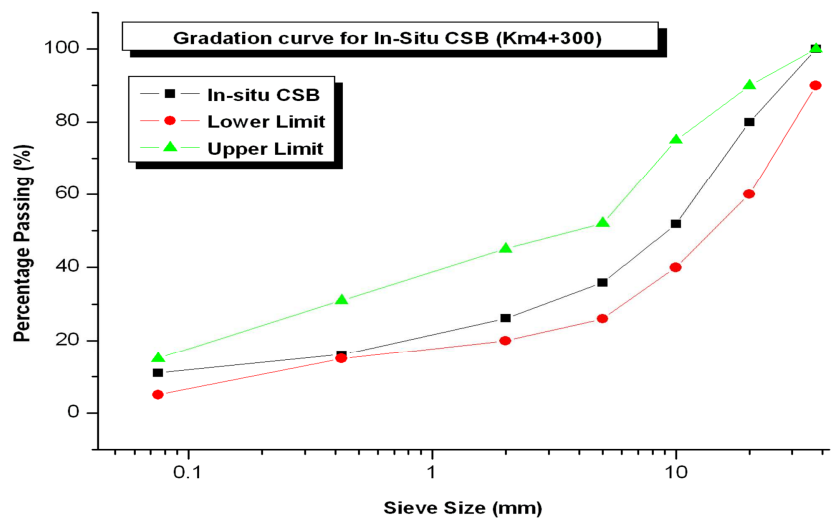

Figure 11. Particle size distribution of CSB material

Hence, on the whole, compliance of the DBM material with the particle size distribution requirement of the MRH Specification was not total. 
c) Sub-base and Crushed Stone Base Layers

Figures 11 and 12 show the particle size distribution curves of the CSB material and the sub-base, respectively. It is seen from the curves that whereas compliance with the MRH specification for the base material was total, it was not so for the sub-base material. The fines fraction of some of the samples went above the upper limits of the specification.

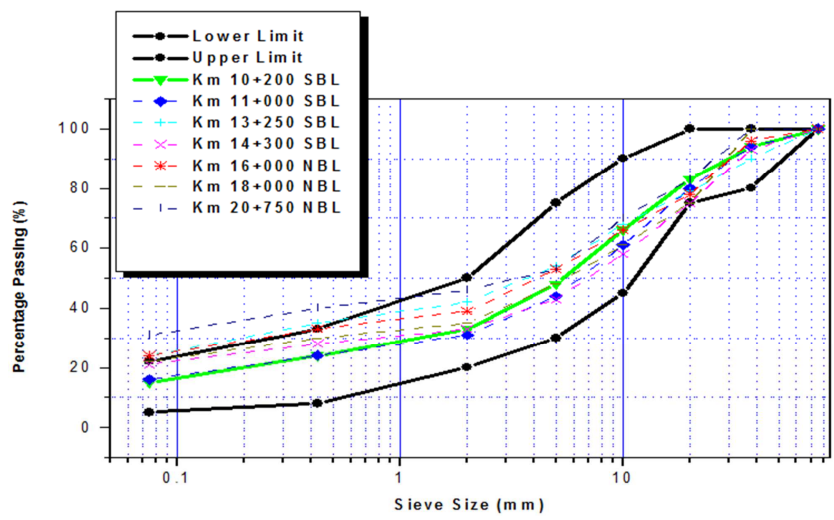

Figure 12. Particle size distribution of sub-base material.

\subsection{Geotextile Placement}

In the course of the fieldwork, a geotextile material placed in an earlier intervention work was established to have been placed at a depth with only about $15-20 \mathrm{~mm}$ asphalt concrete cover (see Fig. 13). Literature on geotextile placement in asphalt overlays recommends a minimum compacted cover of $38 \mathrm{~mm}$ (1.5inches) as first lift [2] to make it effective. This suggests that the placement of the geotextile did not meet this minimum requirement and probably partly explains why the material had not been effective in arresting cracks.

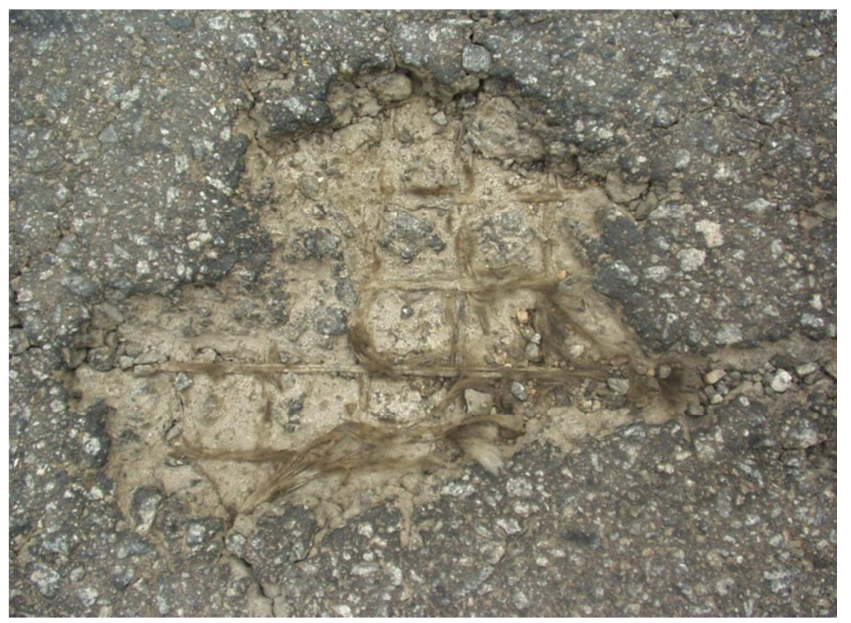

Figure 13. Exposed geotextile placed in an earlier maintenance intervention with thin cover.

\section{Conclusions}

Field investigations and laboratory tests conducted in this study were aimed at investigating the premature failure of the Apedwa-Bunsu Junction section of Route N6. Properties of pavement materials and construction quality at several locations along the section were investigated. It was established that poor construction quality and, in some cases, the use of sub-standard pavement materials were the major causes of the many defects on the road. In particular, densities of the bituminous layers (wearing course, binder course and DBM layer), in most cases, did not meet requirements of the technical specifications. The low compaction resulted in a permeable overlay that facilitated moisture penetration from below and above to cause moisture-induced damage. The DBM layer did not benefit from the asphalt binder within the matrix nor exhibit the characteristics of a reinforcing layer because of moisture damage effects. High stiffness modulus values of the bituminous layers suggested possible premature aging of the asphalt binder which contributed to the many cracks observed on the road. The presence of plastic fines in the crushed rock base at some locations was suggestive of the presence of clayey material, with the fines content in most locations exceeding specification limits. A geotextile material placed earlier as an intervention measure to arrest cracks was ineffective because it had been placed within the wearing course with insufficient asphalt concrete cover.

\section{References}

[1] Himeno, K., and Watnabe, T. (1987). Design of Asphalt Pavements. Sixth Int. Conf. on Structural Design of Asphalt Pavements. Ann-Abor, Michigan.

[2] Button, J. and Lytton, R. (2003). Guidelines for using geosnythetics with HMA overlays to reduce reflective cracking; Transportation Research Institute, Report No. 1777-P2, Texas A\&M University. Available at http://www.utexas.edu/research/tppc/pubs/button_geosyntheti cs.pdf

[3] Si, W., Ma, B., Li, N., Ren. J. and Wang, H. (2014). Reliability-based assessment of deteriorating performance to asphalt pavement under freeze-thaw cycles in cold regions. Construction and Building Materials, 68 (2014): 572-579.

[4] Chen, D., Bilyeu, J., Scullion, T., Lin, D. and Zhou, F. (2003). "Forensic Evaluation of Premature Failures of Texas Specific Pavement Study-1 Sections." J. Perform. Constr. Facil., 10.1061/(ASCE)0887-3828(2003)17: 2 (67), 67-74.

[5] Horak, E. and Emery, S. J. (2010). Forensic Investigation to determine the reasons for premature failure in asphalt surface layer. Road Materials and Pavement Design, 11(3): 511-527.

[6] Muench, S. and Willoughby, K. (2006). Preventing pavement failure caused by hot-mix asphalt pavement temperature differentials: Washington State's systematic approach. TR News 246, September-October 2006, pp 26-28.

[7] Gubler, R., Partl, M. N., Canestrari, F. and Grilli, A. (2005). Influence of water and temperature on mechanical properties of selected asphalt pavements. Materials and Structures, 38(5): 523-532.

[8] Anochie-Boateng, J. K, Mataka, M. O., Malisa, J. T. and Komba, J. J. (2015). Forensic study into the causes of premature failures in asphalt pavements in Tanzania. Road pavements of the XXVth World Road Congress in Seoul, Seoul, South Korea, November 2015. 
[9] Vrtis, M. and Timm, D. (2015). Case Study on Premature Pavement Failure and Successful Reconstruction of a High RAP Section at the NCAT Test Track. Airfield and Highway Pavements 2015: pp. 260-271. doi: $10.1061 / 9780784479216.024$

[10] Mohammad, L. N., Elseifi, M. A., Bae, A., Patel, N., Button, J. N. and Scherocman, J. A. (2012). Optimization of tack coat for HMA placement. National Cooperative Highway Research Program, Report No. 712. Available at http://onlinepubs.trb.org/onlinepubs/nchrp/nchro_rpt_712.pdf
[11] BS DD213 (1993). Method for determination of the indirect tensile stiffness modulus of bituminous mixtures. British Standard Institutions, London.

[12] Chen, D. (2009). "Investigation of a Pavement Premature Failure on a Weak and Moisture Susceptible Base." Journal of Performance of Constructed Facilities, 23 (5): 309-313

[13] MRH (2007). Specifications for Road Works and Bridges, Ministry of Roads and Highways, Accra, Ghana. 